\title{
Prevalence and Associated Factors of Vitamin A Deficiency among Children and Women in Senegal
}

\author{
Mane Hélène Faye ${ }^{1}$, Nicole Idohou-Dossou ${ }^{1}$, Abdou Badiane ${ }^{1}$, Anta Agne-Djigo ${ }^{2}$, Papa Mamadou DD Sylla ${ }^{1}$, Adama \\ Diouf ${ }^{1}$, Amadou Tidiane Guiro ${ }^{1}$, Salimata Wade $^{1}$ \\ ${ }^{1}$ Laboratoire de Recherche en Nutrition et Alimentation Humaine, Département de Biologie Animale, Faculté des Sciences et Techniques, \\ Université Cheikh Anta Diop de Dakar. BP 5005, Dakar-Fann. Sénégal \\ ${ }^{2}$ Équipe de Recherche Santé et Nutrition, Département Santé Communautaire, UFR Santé et Development Durable, Université Alioune Diop de \\ Bambey, Diourbel
}

\begin{abstract}
Received: 24 April , 2020; Accepted: 8 June, 2020; Published: 21 July 2020
*Corresponding author: Mane Hélène Faye, Laboratoire de Recherche en Nutrition et Alimentation Humaine, Département de Biologie Animale, Faculté des Sciences et Techniques, Université Cheikh Anta Diop de Dakar. BP 5005, Dakar-Fann. Sénégal, Tel. No: +221 775334199, E-mail: manehelene.faye@ucad.edu.sn
\end{abstract}

\begin{abstract}
Background: Like many developing countries, Senegal does not have data on the extent of vitamin A deficiency (VAD) that is representative of its population. The present survey was conducted to fill this gap and to identify factors associated with VAD, prior to the introduction of a large-scale vitamin A oil fortification program.
\end{abstract}

Procedures: A nationwide representative cross-sectional survey involving 1887 children 12 to 59 months old and 1316 women of reproductive age (WRA) was conducted. Blood samples were collected and plasma concentrations of retinol (PR), C-reactive protein (CRP), and alpha-1-acidglycoprotein were measured. PR was adjusted for subclinical inflammation using the BRINDA regression methodology. Multivariate logistic regression was used to identify factors associated with VAD.

Findings: The adjusted prevalence of VAD (PR $\leq 0.7 \mu \mathrm{mol} / \mathrm{L}$ ) in children was $15.3 \%$ and differed by age group, area of residence, and socioeconomic status and half of them had subclinical inflammation. Among WRA, VAD was low (2.3\%) and $18.1 \%$ had vitamin A insufficiency (VAI). Pregnant women were more affected by VAI (28.4\%) and Dakar had lower figures compared with other cities and rural strata. Prevalence of VAI decreased with increasing wealth quintile. In logistic regression, abnormal CRP, poverty, scarce consumption of poultry, oysters, melon, red palm oil, palm kernel oil, Saba senegalensis fruit pulp (Maad) and cowpea, frequent consumption of leeks and consumption of Leptadenia hastata leaves (Mbuum tiakhat), were associated with VAD in children. For women, lower socioeconomic status, fair or poor health status and anemia were negatively associated with VAI.

Conclusions: In Senegal, VAD is a moderate public health problem in children and slight among women. Particular attention should be paid to children older than 23 months, pregnant women, rural populations, and poorest households. Nutritional interventions should be implemented alongside morbidity prevention and control.

Keywords: vitamin A deficiency, children 12-59 months, women of reproductive age, Senegal.

\section{Introduction}

Vitamin $\mathrm{A}$ is an essential nutrient involved in several biological processes including metabolism, hematopoiesis, embryogenesis, immune response, vision, reproduction, and growth [1]. Vitamin A deficiency (VAD) occurs mainly with low dietary intakes, impaired absorption of vitamin A or provitamin A carotenoids, and/or demand increased due to infections or life cycle. The consequences of VAD include the development of night blindness and ocular clinical signs, which can lead to full vision loss; anemia; and low resistance to infections, which increases the risk of morbidity and mortality [2-3].

Children under five years and Women of Reproductive Age (WRA) are the greatest vulnerable groups at risk for VAD according to the WHO [2]. Subclinical VAD affects more than $30 \%$ of under five year old children globally with the highest prevalence rate observed in sub-Saharan Africa (48\%) [4]. Recent data suggested that VAD is the underlying cause of $2 \%$ of all deaths in this age group and the leading cause of preventable blindness. West African countries with published VAD figures indicated a public health problem in children with data varying from $7.3 \%$ to $63.1 \%$ in Liberia, Sierra Leone, Gambia, Ghana, Ivory Coast, Burkina-Faso, Nigeria, Benin, Guinea-Bissau and Mali [5-14]. WRA, especially pregnant women are also affected (19.1 million) and Africa represents over $20 \%$ of the global burden [2].

In 2009, Senegal, as in most developing countries, had limited data on the magnitude of VAD, which were either estimations or sub-national, outdated, and/or based on non-biochemical indicators. Using impression cytology, VAD was found in $11.4 \%$ of children aged 2-6 years in the rural area of the groundnut belt of Senegal [15]. Outlined biochemical results in children indicated a 
VAD public health problem in the Department of Linguère (Louga region) and in Bambey, Kebemer, and Koungheul with prevalence of $71.5 \%$ and $26.1 \%$ in 1993 and 1997, respectively [16-17]. According to MI/UNICEF and the WHO, prevalence of VAD was estimated to be $61 \%$ (2004) and $37 \%(2005)$ [2, 18]. In women, statistics were disparate between geographical areas and over time, ranging from $57.1 \%$ to $2.5 \%$ between 1997 and 2006 while WHO estimated a national prevalence of $19.4 \%$ among pregnant women in 2009 [2,18-20]. Night blindness was reported to affect $2 \%$ of women in Senegal [21]. Therefore, there was a real need for more accurate and representative data prior to the introduction of a large-scale vitamin A oil fortification program. To effectively address VAD at the population level, biological data on its extent were needed.

Several indicators of vitamin A status and their usefulness were already described [22-23]. Plasma retinol (PR), even if not reliable in diagnosing VAD in individuals due to its homeostatic control, is informative in assessing the severity of VAD among populations. However, retinol is altered during inflammation or infection by as much as $25 \%$, leading to inaccurate estimations of deficiency in populations with high prevalence of infection [23-25]. As infection and inflammation are accompanied by an increase in the plasma concentration of acute phase proteins, their measure should be performed to adequately interpret PR concentration.

Thus, the aim of this survey was to assess, for the first time, the national prevalence of VAD and its determinants among children 12 to 59 months and WRA in Senegal.

\section{Methods}

\section{Study Design and Population}

A nationwide representative cross-sectional survey, involving children 12 to 59 months and WRA 15 to 49 years, was conducted during the dry season, from April to May 2010. According to food consumption and socioeconomic patterns, Senegal was stratified into 4 areas: Urban Dakar, Other urban cities, Rural 1 (rural areas of Tambacounda, Kedougou, Kolda, Sedhiou, and Ziguinchor regions) and Rural 2 (rural areas of Matam, Saint Louis, Louga, Thies, Diourbel, Fatick, Kaolack, Kaffrine, and Dakar). A twostage stratified cluster sampling procedure with probability proportional to size was carried out to randomly select 1810 households from 57 clusters. The sample size calculation for women was based on prevalence of VAD during wet season (7\%) reported by Gueye [20] in rural women of Sedhiou, southern Senegal. Considering a design effect of 2.9 and a precision of $5.0 \%$, the minimal sample size required was 915 women. Using the above parameters and considering a prevalence of VAD of 61\% [18], the sample size needed was 1104 for children aged 12 to 59 months. The survey protocol was approved by the ethical committee of the Senegalese Ministry of Health (CNERS). Women and children were eligible if informed written consent was provided by the heads of households, women, and children's mothers or caregivers.

\section{Data Collection Procedures}

Questionnaires were used to collect subjects' socioeconomic, socio-demographic, food consumption, and health history data.

Socioeconomic data included information on housing (occupancy status, drinking water source, type of toilet facilities, type of fuel used for cooking, type of household lighting) and ownership of durable goods (household equipment and livestock). These data were analyzed to generate a household's socioeconomic status indicator (wealth quintile) consisting of 5 categories (poorest, poor, intermediate, relatively wealthy, and wealthiest). Main sociodemographic data collected were physiological status (pregnant, breastfeeding, non-pregnant/ non-breastfeeding) for women and gender and age for children. Children's food consumption habits (breastfeeding and complementary feeding practices) were reported as well as food frequency data and women's knowledge on vitamin A-rich foods. Health status and presence of clinical signs of VAD among children and women were carried out by physicians based on their medical history and physical examination. In addition, anemia status of children and women was investigated.

\section{Blood Collection and Biological Measurement}

Blood collection was performed by medical staff. Ten (10) and 5-7 milliliters of blood were drawn from women and children, respectively, by venipuncture using a single-use syringe, and metal-free vacuum collection tube containing lithium heparin as anticoagulant (Sarstedt). Hemoglobin (Hb) concentrations were measured on a drop of whole blood using an HemoCue $\AA$ $201+$ portable device (HemoCue AB) while the remaining sample was centrifuged at $3200 \mathrm{rpm}$ for 12 minutes and plasma stored at $-20^{\circ} \mathrm{C}$ in the field and kept at $-80{ }^{\circ} \mathrm{C}$ in the laboratory until analysis. Plasma handling was done away from dust, under minimal light, and wrapped with aluminum foil to protect lightsensitive compounds from degradation. Samples were analyzed for plasma retinol (PR), C-reactive protein (CRP) and alpha-1 acid glycoprotein (AGP) in the Laboratoire de Recherche en Nutrition et Alimentation Humaine, Université Cheikh Anta Diop, Dakar, Senegal.

PR analysis was performed by high performance liquid chromatography using a methodology previously described [26] using a Spectra SYSTEM (Thermo Electron SAS) consisting of an SCM1000 vacuum membrane degasser, a pump P1000XR, an autosampler AS3000, a UV6000LP detector, and a SN 4000 module.

CRP and AGP concentrations were measured by immunoturbidimetry using a Biosystems A15 automatic analyzer (Biosystems S.A.) with Biosystems kit reagents.

\section{Cutoffs}

PR concentration $<1.05 \mu \mathrm{mol} / \mathrm{L}$ was used to define vitamin A insufficiency (VAI) in women and $\mathrm{PR} \leq 0.7 \mu \mathrm{mol} / \mathrm{L}$ was used to define VAD both in women and children [22-23]. Inflammation 


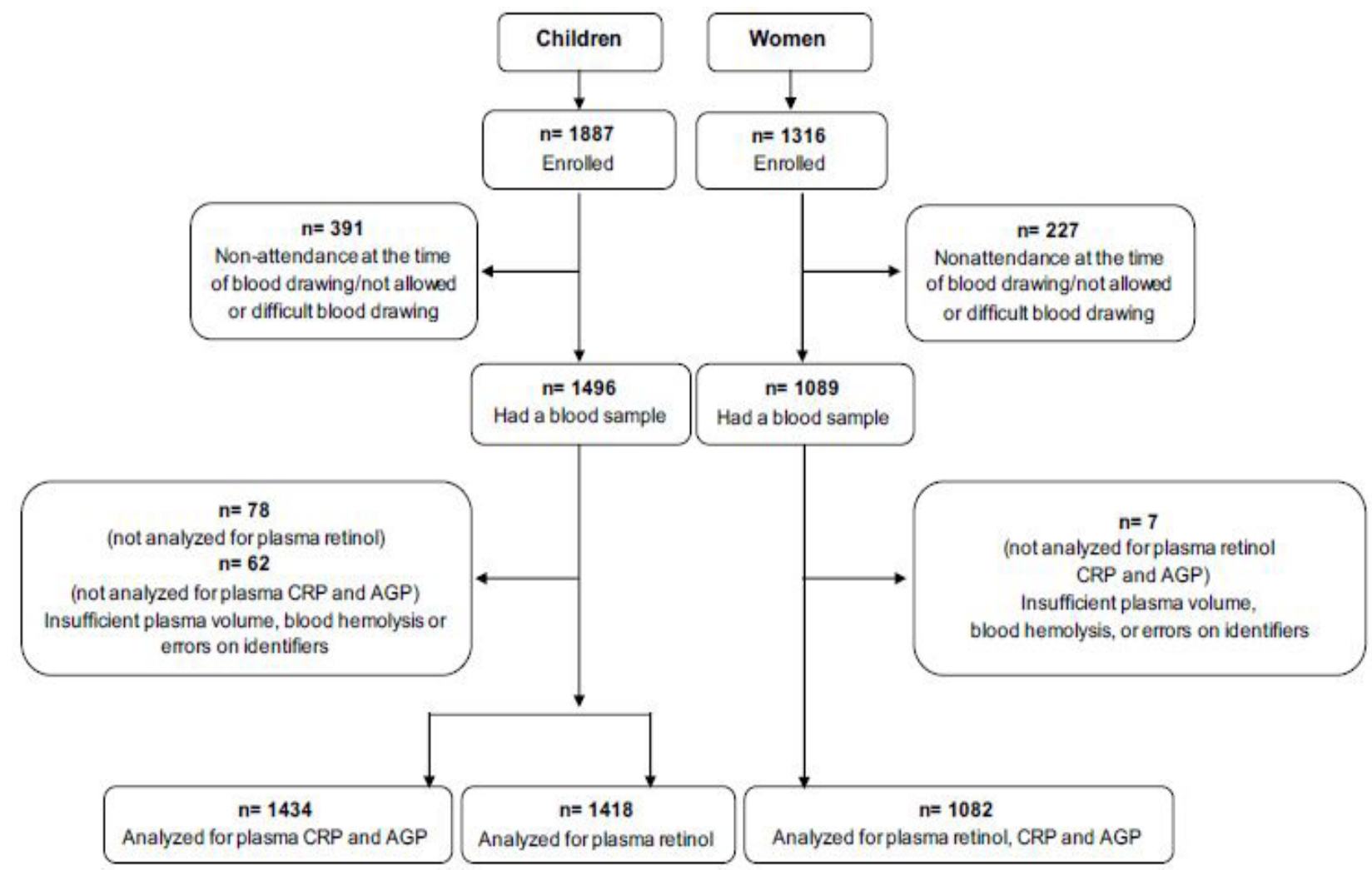

Figure 1: Flow chart of children 12 to 59 months and WRA recruited into a study to evaluate the national prevalence of VAD in Senegal, 2010

status was defined as CRP $>5 \mathrm{mg} / \mathrm{L}$ and/or AGP $>1 \mathrm{~g} / \mathrm{L}$ [25]. Anemia was defined by $\mathrm{Hb}$ concentration $<110 \mathrm{~g} / \mathrm{L}$ in children and pregnant women and $\mathrm{Hb}$ concentration $<120 \mathrm{~g} / \mathrm{L}$ in nonpregnant women [27].

\section{Adjustment of PR Concentration for Inflammation Using BRINDA Methodology}

PR concentration was adjusted for subclinical inflammation using the regression correction approach developed by the BRINDA project as previously described [28-29] and prevalence of VAD was derived from those values. Briefly, adjusted PR values were obtained by subtracting the influence of CRP and AGP as follows: Retinoladjusted $=$ retinolunadjusted $-\beta 1$ (CRPobs CRPref) - $\beta 2$ (AGPobs - AGPref). In this equation, $\beta 1$ and $\beta 2$ are regression coefficients of CRP and AGP, respectively, obs is the individual observed value and ref is the reference value. Retinol, CRPobs, CRPref, AGPobs and AGPref are on natural logarithm scale. Internal reference values from our dataset (maximum value of the lowest CRP or AGP decile or $10^{\text {th }}$ percentile obtained) were used. Unlogged CRPref was $0.1 \mathrm{mg} / \mathrm{L}$ both for children and women while AGPref was $0.65 \mathrm{~g} / \mathrm{L}$ and $0.55 \mathrm{~g} / \mathrm{L}$ in children and women, respectively. Adjustments were only applied to individuals with either CRP concentrations> CRPref, AGP concentrations> AGPref or both. PR-adjusted values were back-transformed before applying cutoffs.

\section{Statistical Analysis}

Statistical analysis was performed using SPSS 15 (SPSS for Windows) and STATA/SE version 11.0 (STATA Corporation). Data were weighted for national representativeness of the results. Categorical variables were expressed as percentages, and continuous variables were expressed as means $\pm S D$, except for CRP which was not normally distributed. Plasma concentrations of CRP were log-transformed and expressed as geometric means with $95 \%$ confidence interval [CI]. Student's t-test and analysis of variance (ANOVA) associated to a Bonferroni correction were used to compare means. Pearson's chi-squared was used to compare percentages. Comparisons were also done between age and sex groups in children, according to their physiological condition in women (pregnant, breastfeeding, non-pregnant/ non-breastfeeding), and by area of residence for both children and women. Relation between PR and inflammation biomarkers was studied using Pearson's correlation coefficient (r). Multiple logistic regression model was used to assess association of socioeconomic, dietary, and health factors with VAD. For all statistical analyses, a significance level of 0.05 was used. 


\section{Results}

\section{Characteristics of the Study Population}

In this study, 1316 WRA and 1887 children aged 12 to 59 months were targeted and PR concentration was measured on 1082 WRA and 1418 children [Figure 1]. Sociodemographic and health-related characteristics of the study population are presented in Table 1.

Table 1: Sociodemographic and health related characteristics of the study population

\begin{tabular}{|c|c|c|}
\hline Characteristic & $\mathbf{n}$ & $\%$ \\
\hline \multicolumn{3}{|l|}{ Children } \\
\hline \multicolumn{3}{|l|}{ Age group, months } \\
\hline $12-23$ & 462 & 24.2 \\
\hline $24-35$ & 485 & 25.8 \\
\hline $36-47$ & 480 & 26.2 \\
\hline $48-59$ & 442 & 23.8 \\
\hline \multicolumn{3}{|l|}{ Gender } \\
\hline Girls & 948 & 50.1 \\
\hline \multicolumn{3}{|l|}{ Illness (within last 15 days) } \\
\hline Fever & 395 & 65.7 \\
\hline Diarrhoea & 119 & 25.1 \\
\hline $\begin{array}{l}\text { Cough/ breathing } \\
\text { trouble }\end{array}$ & 198 & 40.1 \\
\hline VAS (within last 6 months) ${ }^{1}$ & 1079 & 78.5 \\
\hline $\begin{array}{l}\text { Deworming (within last } 6 \\
\text { months) }\end{array}$ & 1068 & 77.7 \\
\hline Anemia & 967 & 66.1 \\
\hline \multicolumn{3}{|l|}{ Women } \\
\hline \multicolumn{3}{|l|}{ Age group, years } \\
\hline $15-19$ & 286 & 20.5 \\
\hline $20-24$ & 283 & 22.5 \\
\hline $25-29$ & 199 & 16.2 \\
\hline $30-34$ & 187 & 13.7 \\
\hline $35-39$ & 145 & 10.7 \\
\hline $40-44$ & 121 & 10.2 \\
\hline $45-49$ & 92 & 6.1 \\
\hline \multicolumn{3}{|l|}{ Physiological status } \\
\hline Pregnant & 100 & 8.8 \\
\hline Lactating & 270 & 25 \\
\hline $\mathrm{NPNL}^{2}$ & 713 & 66.2 \\
\hline Night blindness & 18 & 3.9 \\
\hline Clinical signs of VAD & 60 & 8 \\
\hline Anemia & 498 & 47.5 \\
\hline \multicolumn{3}{|c|}{${ }^{1}$ VAS: vitamin A supplementation } \\
\hline${ }^{2}$ NPNL: Non-Pregnant-Non-La & & \\
\hline
\end{tabular}

Among the children, the mean age was $34.3 \pm 13.0$ months. Their proportion was almost equal between age groups while girls represented $50.1 \%$ of the children. Within the 15 days prior to the survey, fever, diarrhea, and cough/breathing trouble related to illness were reported in $65.7 \%, 25.1 \%$, and $40.1 \%$ of children, respectively. Coverage of vitamin A supplementation in children within the last 6 months preceding the survey was $78.5 \%(\mathrm{n}=1079)$ with disparities among strata (Dakar: 20.5\%; Other cities: 84.4\%; Rural 1: 51\%; Rural 2: 95.2\%). Among these, $77.7 \%$ were dewormed in the same period. The breastfeeding rate among children under 2 years was $98.1 \%(n=156)$. No case of night blindness was observed among the children. Mean age of WRA was $28 \pm 9$ years. Women aged 20-24 (22.5\%) and 15-19 years $(20.5 \%)$ were the most represented. The sample included $8.8 \%$ pregnant, $25 \%$ lactating, and $66.2 \%$ non-pregnant/nonlactating women (NPNL). Night blindness affected 3.9\% ( $n=18)$ of women in their last pregnancy that resulted in a live birth during the past 3 years. Clinical signs of VAD were reported in $8 \%(n=60)$ of women. Anemia affected $66.1 \%(n=967)$ of children and $47.5 \%(n=498)$ of women.

\section{Subclinical Inflammation among the Study Population}

Inflammation was widespread and involved 1 out of 2 children, regardless of gender. Prevalence of inflammation decreased with age and the children aged 12-23 months and 2435 months were the most affected groups [Table 2]. Among the women, over one quarter were affected by inflammation with significant differences according to their physiological status and the area of residence. The prevalence of inflammation in women was higher in Dakar compared to other cities and Rural $1(P<$ 0.01).

Plasma Retinol Concentration and Prevalence of vitamin A Deficiency Among Children

PR concentration was normally distributed among children and its mean value was $0.90 \pm 0.26 \mu \mathrm{mol} / \mathrm{L}$ [min: 0.16 ; max: 1.85] [Table 3]. According to gender, mean PR was higher in girls compared with boys $(P<0.01)$. PR concentration was significantly higher in children aged 12-23 months compared with those in 24-35 $(P<0.01), 36-47(P<0.001)$, and 48-59 $(P$ $<0.05$ ) months groups. According to their area of residence, no significant difference was observed in PR concentration between urban strata. The same scheme was observed between rural strata. However, mean PR concentration of children in urban strata were higher than in rural strata $(P<0.001)$. In addition, $P R$ concentration increased meaningfully with socioeconomic status $(P<0.05)$.

According to inflammation status, both CRP and AGP were negatively and significantly associated with PR of children (CRP: $r=-0.1162, P<0.001$; AGP: $r=-0.1790, P<0.001$ ). Inflammation adjustment was done on PR using the BRINDA regression methodology. After adjustment with inflammation, mean PR concentration of children significantly increased (0.9 \pm 0.26 vs. $0.99 \pm 0.28 \mu \mathrm{mol} / \mathrm{L}, P<0.001$ ) and the difference observed between groups (gender, age, area of residence, and socioeconomic status) persisted. The prevalence of VAD after inflammation-adjustment in 12-59 months aged children was $15.3 \%$ [Table 3] with $0.1 \%$ severe cases [Table 5]. Prevalence of VAD was comparable between gender groups but significantly higher in 24-35 and 36-47-months aged children compared to 
Table 2: Extent of subclinical inflammation among children and women ${ }^{1}$

\begin{tabular}{|c|c|c|c|c|c|}
\hline & \multirow[b]{2}{*}{$\mathbf{n}$} & \multirow[b]{2}{*}{ Any inflammation ${ }^{3}$} & \multicolumn{3}{|c|}{ Stage of inflammation ${ }^{2}$} \\
\hline & & & Incubation & Early convalescence & Late convalescence \\
\hline \multicolumn{6}{|l|}{ Children } \\
\hline National & 1434 & 50.1 & 6.2 & 12.7 & 31.2 \\
\hline \multicolumn{6}{|l|}{ Gender } \\
\hline Male & 712 & 52.5 & 7 & 11.3 & 34.1 \\
\hline Female & 722 & 47.7 & 5.3 & 14.1 & 28.3 \\
\hline \multicolumn{6}{|c|}{ Age group, months } \\
\hline $12-23$ & 330 & $65.5^{\mathrm{a}}$ & 6.7 & 20.6 & 38.2 \\
\hline $24-35$ & 359 & $54.8^{\mathrm{b}}$ & 6.2 & 10.7 & 37.8 \\
\hline $36-47$ & 376 & $46.0^{c}$ & 7.9 & 12.8 & 25.3 \\
\hline $48-59$ & 132 & $36.5^{d}$ & 3.9 & 7.8 & 24.7 \\
\hline \multicolumn{6}{|l|}{ Area of residence } \\
\hline Dakar & 190 & $58.7^{\mathrm{a}}$ & 16.6 & 14.9 & 27.3 \\
\hline Other cities & 310 & $42.0^{\mathrm{b}}$ & 5.4 & 12.7 & 24 \\
\hline Rural 1 & 382 & $43.0^{c}$ & 1.8 & 8.2 & 33 \\
\hline Rural 2 & 552 & $52.7^{\mathrm{a}, \mathrm{b}, \mathrm{d}}$ & 5 & 13.2 & 34.4 \\
\hline \multicolumn{6}{|l|}{ Women } \\
\hline National & 1082 & 27.7 & 10.8 & 6.6 & 10.3 \\
\hline \multicolumn{6}{|c|}{ Physiological status } \\
\hline Pregnant & 99 & $26.9^{\mathrm{a}}$ & 20.6 & 2.1 & 4.2 \\
\hline Lactating & 267 & $34.4^{\mathrm{a}, \mathrm{b}}$ & 9 & 9.5 & 15.9 \\
\hline $\mathrm{NPNL}^{4}$ & 707 & $25.8^{b, c}$ & 10.4 & 6.2 & 9.1 \\
\hline \multicolumn{6}{|l|}{ Area of residence } \\
\hline Dakar & 293 & $33.3^{\mathrm{a}}$ & 14.5 & 7 & 11.8 \\
\hline Other cities & 182 & $29.8^{a, b}$ & 7.7 & 9 & 13.2 \\
\hline Rural 1 & 217 & $16.3^{c}$ & 3.4 & 8 & 4.9 \\
\hline Rural 2 & 390 & $22.8^{\mathrm{b}, \mathrm{d}}$ & 9.1 & 4.9 & 8.7 \\
\hline
\end{tabular}

${ }^{1}$ Values are \%. For each indicator, values between category of groups (in columns) with different superscript letters (a, b, c and d) are significantly different, $\mathrm{P}<0.05$

${ }^{2}$ Stage of inflammation: incubation (CRP $>5 \mathrm{mg} / \mathrm{L}$ and $\mathrm{AGP} \leq 1 \mathrm{~g} / \mathrm{L}$ ); early convalescence (CRP $>5 \mathrm{mg} / \mathrm{L}$ and AGP $>1 \mathrm{~g} / \mathrm{L}$ ); late convalescence (AGP $>1$ $\mathrm{g} / \mathrm{L}$ and $\mathrm{CRP} \leq 5 \mathrm{mg} / \mathrm{L}$ )

${ }^{3}$ Any inflammation: $\mathrm{CRP}>5 \mathrm{mg} / \mathrm{L}$ and/ or AGP $>1 \mathrm{~g} / \mathrm{L}$

${ }^{4}$ NPNL: Non-Pregnant-Non-Lactating

those aged 12-23 months. According to areas of residence, Rural 1 and Rural 2 had comparable figures but both presented higher prevalence of VAD than urban strata $(P<0.001)$. Children in the poorest households had a higher prevalence of VAD than in other household wealth categories.

Plasma Retinol Concentration and Prevalence of Vitamin A Deficiency among Women

Overall, mean PR concentration of WRA was $1.43 \pm 0.44$ $\mu \mathrm{mol} / \mathrm{L}$ [min: 0.355; max: 3.851] [Table 4]. In WRA, weak but significant and negative correlation was observed between PR and CRP ( $\mathrm{r}=-0.069, \mathrm{P}=0.042$ ) while no relationship was observed with AGP $(\mathrm{r}=0.033, \mathrm{P}=0.274)$. Because of this weak relationship between inflammation and retinol in women, PR was not adjusted and the prevalence of VAD was estimated from non-adjusted values. Vitamin A insufficiency (VAI) was present in $18.1 \%$ of women among which $2.3 \%$ had VAD and $15.7 \%$ marginal vitamin A status [Table 5]. Mean PR was associated with physiological status and was lower in pregnant women compared with lactating $(P=0.002)$ and NPNL women $(P<0.001)$. Thus, the prevalence of VAI was higher in pregnant women $(28.4 \%)$, comparable to lactating women but significantly different from
NPNL women $(P<0.001)$. Furthermore, when women were separated into 2 groups (Pregnant vs Non-pregnant), VAI was higher in pregnant women $(28.4 \%$ vs.17.2\%, $P<0.01)$. According to the area of residence, $P R$ concentration was significantly higher in urban Dakar $(P<0.001)$. Consequently, prevalence of VAI was significantly different among strata, lower in Dakar compared with others cities $(P<0.01)$ and rural strata $(P<0.001)$. Significant differences were also observed using socioeconomic status and consequently prevalence of VAI decreased with increasing wealth quintile from $37 \%$ in the poorest to $9.1 \%$ in the wealthiest $(P<$ 0.001).

Factors associated with vitamin A deficiency among children

Logistic regression analysis [Table 6] showed that poverty status was associated with children's risk of VAD. Indeed, children from poorest, poor, and intermediate socioeconomic status households had 5.64, 2.33 and 4 times greater risk of VAD, respectively $(P<0.01)$ than their wealthiest peers. Incubation phase of inflammation was also a risk factor for low PR in this population group. Regression from dietary patterns showed that 
Table 3: Plasma retinol concentrations and VAD prevalence according to gender, age group, area of residence and socioeconomic status among children ${ }^{1}$

\begin{tabular}{|c|c|c|c|c|c|}
\hline & \multirow[b]{2}{*}{$\mathbf{n}$} & \multicolumn{2}{|c|}{ Plasma retinol $(\mu \mathrm{mol} / \mathrm{L})$} & \multicolumn{2}{|l|}{ VAD (\%) } \\
\hline & & Unadjusted & Adjusted $^{2}$ & Unadjusted & Adjusted $^{2}$ \\
\hline National & 1418 & $0.9 \pm 0.26$ & $0.99 \pm 0.28$ & 24.5 & 15.3 \\
\hline \multicolumn{6}{|l|}{ Gender } \\
\hline Girls & 702 & $0.88 \pm 0.24^{\mathrm{a}}$ & $0.97 \pm 0.26^{\mathrm{a}}$ & 26.4 & 16.3 \\
\hline Boys & 716 & $0.92 \pm 0.27^{b}$ & $1.0 \pm 0.3^{\mathrm{b}}$ & 22.6 & 14.3 \\
\hline \multicolumn{6}{|l|}{ Age group, months } \\
\hline $12-23$ & 324 & $0.96 \pm 0.28^{c}$ & $1.1 \pm 0.3^{c}$ & $19.4^{c}$ & $9.9^{c}$ \\
\hline $24-35$ & 353 & $0.89 \pm 0.26^{d}$ & $0.98 \pm 0.29^{d}$ & $26.6^{d}$ & $17.3^{\mathrm{d}}$ \\
\hline $36-47$ & 374 & $0.87 \pm 0.25^{\mathrm{d}}$ & $0.94 \pm 0.27^{\mathrm{d}}$ & $30.2^{\mathrm{e}}$ & $17.9^{d}$ \\
\hline $48-59$ & 366 & $0.90 \pm 0.23^{\mathrm{d}}$ & $0.97 \pm 0.25^{\mathrm{d}}$ & $20.9^{\mathrm{c}, \mathrm{d}}$ & $13.1^{\mathrm{c}, \mathrm{d}}$ \\
\hline \multicolumn{6}{|l|}{ Area of residence } \\
\hline Dakar & 190 & $0.97 \pm 0.24^{\mathrm{a}}$ & $1.1 \pm 0.25^{\mathrm{a}}$ & $15.0^{\mathrm{a}}$ & $6.9^{\mathrm{a}}$ \\
\hline Other cities & 308 & $0.98 \pm 0.26^{\mathrm{a}}$ & $1.1 \pm 0.28^{\mathrm{a}}$ & $14.6^{\mathrm{a}}$ & $8.2^{\mathrm{a}}$ \\
\hline Rural 1 & 377 & $0.87 \pm .25^{\mathrm{b}}$ & $0.95 \pm 0.27^{b}$ & $27.0^{\mathrm{b}}$ & $20.0^{\mathrm{b}}$ \\
\hline Rural 2 & 543 & $0.86 \pm 0.25^{b}$ & $0.95 \pm 0.28^{b}$ & $29.8^{b}$ & $18.4^{\mathrm{b}}$ \\
\hline \multicolumn{6}{|c|}{ Socioeconomic status } \\
\hline Poorest & 298 & $0.82 \pm 0.23^{\mathrm{a}}$ & $0.89 \pm 0.25^{\mathrm{a}}$ & $33.6^{\mathrm{a}}$ & $25.3^{\mathrm{a}}$ \\
\hline Poor & 346 & $0.87 \pm 0.25^{b}$ & $0.95 \pm 0.27^{b}$ & $26.5^{b}$ & $15.6^{\mathrm{b}}$ \\
\hline Intermediate & 313 & $0.89 \pm 0.27^{b}$ & $0.98 \pm 0.3^{b}$ & $29.1^{b}$ & $20.7^{b}$ \\
\hline Wealthy & 263 & $0.96 \pm 0.24^{c}$ & $1.05 \pm 0.26^{c}$ & $14.7^{\mathrm{c}}$ & $5.7^{\mathrm{c}}$ \\
\hline Wealthiest & 193 & $1.0 \pm 0.26^{c}$ & $1.10 \pm 0.28^{c}$ & $14.3^{c}$ & $5.5^{c}$ \\
\hline
\end{tabular}

Table 4: Plasma retinol concentrations and prevalence of VAI according to physiological status, area of residence and socioeconomic status among women ${ }^{1}$

\begin{tabular}{|c|c|c|c|}
\hline & $\mathbf{n}$ & Plasma retinol, $\mu \mathrm{mol} / \mathrm{L}$ & VAI (\%) \\
\hline National & 1082 & $1.43 \pm 0.44$ & 18.1 \\
\hline \multicolumn{4}{|c|}{ Physiological status } \\
\hline Pregnant & 99 & $1.26 \pm 0.38^{\mathrm{a}}$ & $28.4^{\mathrm{a}}$ \\
\hline Lactating & 267 & $1.42 \pm 0.47^{b}$ & $22.3^{\mathrm{a}, \mathrm{b}}$ \\
\hline $\mathrm{NPNL}^{2}$ & 707 & $1.46 \pm 0.43^{b}$ & $15.2^{\mathrm{b}, \mathrm{c}}$ \\
\hline \multicolumn{4}{|l|}{ Area of residence } \\
\hline Dakar & 293 & $1.57 \pm 0.42^{\mathrm{a}}$ & $7.7^{\mathrm{a}}$ \\
\hline Other cities & 182 & $1.4 \pm 0.37^{b}$ & $16.8^{b}$ \\
\hline Rural 1 & 217 & $1.27 \pm 0.42^{\mathrm{b}, \mathrm{c}}$ & $31.8^{c}$ \\
\hline Rural 2 & 390 & $1.3 \pm 0.42^{c}$ & $28.3^{c}$ \\
\hline \multicolumn{4}{|c|}{ Socioeconomic status } \\
\hline Poorest & 193 & $1.2 \pm 0.4^{\mathrm{a}}$ & $37.0^{\mathrm{a}}$ \\
\hline Poor & 174 & $1.3 \pm 0.4^{\mathrm{a}}$ & $29.8^{\mathrm{a}, \mathrm{b}}$ \\
\hline Intermediate & 228 & $1.41 \pm 0.47^{\mathrm{a}, \mathrm{b}}$ & $20.9^{b, c}$ \\
\hline Wealthy & 219 & $1.46 \pm 0.39^{\mathrm{b}, \mathrm{c}}$ & $14.2^{\mathrm{d}}$ \\
\hline Wealthiest & 264 & $1.54 \pm 0.41^{\mathrm{c}}$ & $6.9^{\mathrm{e}}$ \\
\hline
\end{tabular}

rare or no consumption of foods rich in preformed vitamin $A$, vitamin A precursors and or dietary fats was predictive of VAD (poultry, oysters, melon, red palm oil, palm kernel oil). On the other hand, their frequent consumption or simple consumption were found to have significant protective effects $(P<0.05)$ on children' $\mathrm{s}$ VAD (Saba senegalensis fruit pulp, leeks) at the exception of Leptadenia hastata leaves (OR=1.91). Only rare consumption of cowpea was found to be protective for VAD (OR=0.47).

\section{Women \\ Factors Associated with Vitamin A Insufficiency among}

Among women, the odds of VAI increased with lower socioeconomic status. Hence, compared with women from 
the wealthiest households, those from relatively wealthy, intermediate, poor and poorest households had 2.53, 5.32, 5.95, and 8.44 greater risk of VAI, respectively [Table 6.] In addition, fair $(\mathrm{OR}=2.51)$ and poor $(\mathrm{OR}=7.96)$ health status as well as anemia status $(\mathrm{OR}=1.88)$ were negatively associated with VAI in women.

Table 5: Levels of vitamin A deficiency (VAD) among Senegalese children and women

\section{Prevalence of vitamin A deficiency}

$\mathrm{n}$

$\%$

\begin{tabular}{|c|l|l|}
\hline Children $^{\mathbf{1}}$ & 1418 & \\
\hline Normal status & 1210 & 84.7 \\
\hline Marginal VAD & 207 & 15.2 \\
\hline $\begin{array}{c}\text { Severe VAD } \\
\text { Women }^{2}\end{array}$ & 1 & 0.1 \\
\hline Normal status $_{\text {Marginal status }}$ & 1082 & \\
\hline VAD & 1961 & 81.9 \\
\hline & 29 & 15.7 \\
\hline
\end{tabular}

${ }^{1}$ Normal status: PR $>0.7 \mu \mathrm{mol} / \mathrm{L}$, Marginal VAD: $0.35<\mathrm{PR} \leq 0.7 \mu \mathrm{mol} / \mathrm{L}$ ), Severe VAD: $P R \leq 0.35 \mu \mathrm{mol} / \mathrm{L}$

${ }^{2}$ Normal status: $\mathrm{PR} \geq 1.05 \mu \mathrm{mol} / \mathrm{L}$, Marginal VA status: $0.7<\mathrm{PR}<1.05$ $\mu \mathrm{mol} / \mathrm{L}, \mathrm{VAD}: \mathrm{PR} \leq 0.7 \mu \mathrm{mol} / \mathrm{L}$

\section{Discussion}

Nationally, data from the present study revealed that VAD was a moderate public health problem in children aged 12 to 59 months according to the WHO classification criteria using PR as the indicator [23]. Our findings were lower than the estimations of $37 \%$ and $61 \%$ reported by the $\mathrm{WHO}$ and MI/UNICEF, respectively, probably due to the methodology based on regression model estimates using member countries reported studies [2, 18]. The prevalence of VAD observed in our study seems to be lower than those of all West African countries with published national statistics with the exception of Liberia (7.3\%), i.e., Sierra Leone (17.4\%), Gambia (18.3\%), Ghana (20.8\%), Ivory Coast (24.1\%), and Nigeria $(29.5 \%)[5-9,11]$. However, comparison should be done with caution because those data were mainly based on RBP measurement instead of PR concentration as recommended by the WHO for population surveys and used different methods of correction for inflammation, when applicable. Nevertheless, as observed in bivariate analysis, VAD was mild among children 12-23 months and those from urban strata but severe among children living in the poorest wealth quintile households. These dissimilarities might be linked to the higher rate of breastfeeding (98.1\%) in 12-23 months of this study associated with adequate vitamin A status in lactating women and differences in socioeconomic status between urban and rural areas. When comparing unadjusted VAD with subnational figures reported in 1997 (26.1\%), it seems that prevalence of VAD has not substantially decreased over the past decade despite the implementation of vitamin A supplementation (VAS), the only large-scale strategy implemented at the time of the survey which started since 1999 among children under 5 years. VAS coverage has declined between 2005 (75\%) [21] to present (63\%) [30] and its rate stayed below the target of the Senegalese VAS program (95\%) [31]. This situation highlights the need to strengthen the national VAS program and consolidates the VA cooking oil fortification program as a control strategy for VAD with focus on children older than 23 months, children from rural areas, and those living in the poorest households. In less affected population groups, VAD control programs should consider that vitamin A might be provided in excess due to overlapping programs and might cause hypervitaminosis A in the long-term [32], meaning that inclusive population monitoring is needed with biomarkers more sensitive than PR concentrations [33-34].

In multivariate analysis, poverty, abnormal CRP, and scarce or no consumption of several vitamin A food sources were found to be predictive of VAD risk in Senegalese children. Indeed, poor socioeconomic status could have a negative impact on food security by limiting access to sufficient and nutritious food, thus compromising the satisfaction of nutritional requirements of the population [35-36]. It could also affect financial access to adequate care. Moreover, morbidity prevention and control should be consolidated, regarding the high occurrence of illness observed in children that was corroborated by high prevalence of inflammation and the association between VAD and abnormal CRP concentration. Alongside these efforts, nutrition education promoting adequate dietary intake of preformed and / or vitamin A precursors rich foods such as poultry, oysters, melon, leeks, red palm oil and Saba senegalensis fruit pulp should be considered. The risk of VAD associated with consumption of Leptadenia hastata leaves reported to be rich in $\beta$-carotene [37] might be related to the low bioavailability associated with the matrix in which the provitamin carotenoids are incorporated, antinutritional factors, or poverty. In this study, cowpea's rare consumption was found to have a protective effect on VAD. Given the higher protein content of cowpea ( $20 \%$ to $40 \%$ ), its frequent consumption might reduce the activity of the enzyme carotene dioxygenase which is involved in $\beta$-carotene absorption [38], explaining a protective effect in those consuming cowpeas rarely. The protective effect of palm kernel oil on the risk of VAD can be explained by the known improvement effect of dietary fats on vitamin A and provitamin A carotenoid absorption. In addition, even if lacking vitamin A precursors, palm kernel oil could be contaminated from palm fruit pulp during traditional transformation processes. Otherwise, this association needs further investigation.

Among Senegalese women, prevalence of VAD was low (2.3\%), depicting a minor public health problem, while $15.7 \%$ of them was at risk of VAD. The prevalence of VAD is consistent with the $2.5 \%$ found during dry season in the rural area of Sedhiou in 2006 [20]. It is also comparable to Sierra Leone (2.1\%) but slightly over the data from Ghana (1.5\%) and Gambia (1.8\%) [6-8]. Pregnant women were most affected by VAI, probably due to either hemodilution or the $60 \%$ additional vitamin A requirements needed to ensure normal fetal growth, to provide a limited reserve in the fetal liver, and to maintain their own tissue growth [39]. Biochemical results were in line with the reported extent of night blindness among women $(3.9 \%)$, greater than the 


\begin{tabular}{|c|c|c|c|}
\hline & Odds ratio & $95 \% \mathrm{CI}^{1}$ & P value \\
\hline \multicolumn{4}{|l|}{ Children } \\
\hline \multicolumn{4}{|l|}{ Socioeconomic status } \\
\hline Wealthiest & 1 & Ref. & \\
\hline Intermediate & 4 & $2.10-7.64$ & 0.000 \\
\hline Poor & 2.33 & $1.19-4.57$ & 0.013 \\
\hline Poorest & 5.64 & $2.97-10.7$ & 0.000 \\
\hline \multicolumn{4}{|l|}{ Inflammation/Infection ${ }^{2}$} \\
\hline No & 1 & Ref. & \\
\hline Yes & 2.04 & $1.26-3.3$ & 0.004 \\
\hline \multicolumn{4}{|c|}{ Food consumption frequency ${ }^{3}$} \\
\hline \multicolumn{4}{|l|}{ Poultry } \\
\hline Frequent & 1 & Ref. & \\
\hline Rare & 1.78 & $1.14-2.78$ & 0.011 \\
\hline No & 2.05 & $1.08-3.89$ & 0.027 \\
\hline \multicolumn{4}{|l|}{ Oysters } \\
\hline Frequent & 1 & Ref. & \\
\hline Rare & 3.03 & $1.21-7.53$ & 0.017 \\
\hline \multicolumn{4}{|l|}{ Melon } \\
\hline Frequent & 1 & Ref. & \\
\hline Rare & 2.3 & $1.35-3.92$ & 0.002 \\
\hline \multicolumn{4}{|c|}{$\begin{array}{l}\text { Saba senegalensis fruit pulp } \\
\text { (Maad) }\end{array}$} \\
\hline No & 1 & Ref. & \\
\hline Rare & 0.5 & $0.29-0.85$ & 0.011 \\
\hline \multicolumn{4}{|l|}{ Leeks } \\
\hline No & 1 & Ref. & \\
\hline Frequent & 0.1 & $0.014-0.83$ & 0.033 \\
\hline \multicolumn{4}{|l|}{$\begin{array}{l}\text { Leptadenia hastata leaves } \\
\text { (Mbuum tiakhat) }\end{array}$} \\
\hline No & 1 & Ref. & \\
\hline Yes & 1.91 & $1.25-2.92$ & 0.003 \\
\hline \multicolumn{4}{|l|}{ Cowpea } \\
\hline Frequent & 1 & Ref. & \\
\hline Rare & 0.47 & $0.27-0.79$ & 0.005 \\
\hline \multicolumn{4}{|l|}{ Red palm oil } \\
\hline Frequent & 1 & Ref. & \\
\hline No & 1.9 & $1.21-2.98$ & 0.005 \\
\hline \multicolumn{4}{|l|}{ Palm kernel oil } \\
\hline Frequent & 1 & Ref. & \\
\hline No & 2.7 & $1.25-5.83$ & 0.011 \\
\hline \multicolumn{4}{|l|}{ Women } \\
\hline \multicolumn{4}{|l|}{ Socioeconomic status } \\
\hline Wealthiest & 1 & Ref. & \\
\hline Relatively wealthy & 2.53 & $1.26-5.04$ & 0.008 \\
\hline Intermediate & 5.32 & $2.80-10.08$ & 0.000 \\
\hline Poor & 5.95 & $3.08-11.49$ & 0.000 \\
\hline Poorest & 8.44 & $4.46-15.98$ & 0.000 \\
\hline \multicolumn{4}{|l|}{ General health status } \\
\hline Excellent & 1 & Ref. & \\
\hline Fair & 2.51 & $1.5-4.19$ & 0.000 \\
\hline Poor & 7.96 & $2.2-28.82$ & 0.002 \\
\hline \multicolumn{4}{|l|}{ Anemia } \\
\hline No & 1 & Ref. & \\
\hline Yes & 1.88 & $1.33-2.65$ & 0.000 \\
\hline \multicolumn{4}{|l|}{${ }^{1} \mathrm{CI}=$ confidence interval } \\
\hline${ }^{2}$ Incubation (CRP> $5 \mathrm{mg}$ / & $\mathrm{g} / \mathrm{L})$ & & \\
\hline
\end{tabular}


prevalence of $2 \%$ found among Senegalese women in 2005 [21] but below the cutoff point of $5 \%$ defining a public health problem [40].

As for children, poverty was a predictive factor of VAI, the lower the socio-economic status, the higher the risk of VAI. An increased risk of insufficient vitamin A intakes associated with lower socioeconomic status was reported in WRA in Vietnam [41]. Anemia was found to be associated with VAI in Senegalese women. This result supports the well-known relationship between VAD and anemia that has been documented [42-43]. Analogous findings were observed among WRA in Cameroon and Ivory Coast as well as pregnant women in Nepal, India, Iran, Bangladesh, China, and Brazil [44-50]. Even if potential mechanisms by which vitamin A influences anemia have been proposed [43], the pathogenesis of this association remains unclear. However, VAD is known to impair mobilization of iron stores, decreasing iron supplies to the bone marrow and reducing hemoglobin synthesis [51]. Concerning the increased risk of VAI with fair or poor health status, it was likely due to the synergistic relationship between altered vitamin A status and occurrence of infections. This calls to enhanced management of acute inflammation and / or infection particularly, as suggested by the correlation, even weak, between PR and CRP.

\section{Conclusion}

In conclusion, this survey, the first nationally-representative in Senegal, showed that vitamin A deficiency is a moderate public health problem in children and marginal among women. But particular attention must be paid to children over 23 months, pregnant women, rural populations, and the poorest households who are the most vulnerable. Based on reported predictors of VAD among our study population, improvement of VAD in Senegal requires a multiple approach strategy: 1) strengthening the VAS program in order to prevent inflammation and infection related illnesses among children; 2) preventing and controlling anemia among women; 3) implementing the vitamin A fortification program in order to reach high geographical coverage and to make accessible adequately fortified oil, especially for the most vulnerable. This also implies proper monitoring and evaluation to reduce risk of vitamin A excess among groups less affected by VAD; and 4) reinforcing nutrition education by promoting local vitamin A rich products.

\section{Acknowledgements}

The authors appreciate the support of the Comité Sénégalais pour la Fortification des Aliments en Micronutriments (COSFAM) and Nutrition International (Ex Micronutrient Initiative). The authors thank Professor Sherry A. Tanumihardjo for editing the manuscript.

\section{Author Contributions}

MHF participated in data management, performed statistical analysis and drafted the manuscript. SW, ATG, and NID participated in the conceptualization of the study. NID supervised vitamin $\mathrm{A}$ assays. $\mathrm{AD}$ and $\mathrm{AAD}$ participated in data collection and data management. $\mathrm{AB}$ and PMDDS participated in data analysis. All the authors reviewed the manuscript and approved its final submitted version.

\section{Declarations}

\section{Conflict of Interest}

The author(s) declared no conflicts of interest with any financial/research/academic organization with regards to the research, authorship, and/or publication of this article.

\section{Ethical Approval}

The protocol was approved by the ethical committee of the Senegalese Ministry of Health (CNERS) under the reference number SEN 38/08 ITA-COSFAM. Fully informed written consent has been obtained from survey participants.

\section{References}

1. McLaren DS, Kraemer K. Vitamin A in health. World Rev Nutr Diet. 2012;103:33-51. doi: 10.1159/000170954

2. World Health Organization (WHO). Global prevalence of vitamin A deficiency in populations at risk 1995-2005. WHO Global Database on Vitamin A Deficiency. Geneva: World Health Organization, 2009.

3. Wiseman EM, Bar-El Dadon S, Reifen R. The vicious cycle of vitamin A deficiency: A review. Crit Rev Food Sci Nutr. 2017;57(17):3703-3714. doi: 10.1080/10408398.2016.1160362

4. Stevens GA, Bennett JE, Hennocq Q et al. Trends and mortality effects of vitamin A deficiency in children in 138 low-income and middle-income countries between 1991 and 2013: a pooled analysis of population surveys. Lancet Glob Health. 2015;3:e528-36. doi: 10.1016/S2214-109X(15)00039-X

5. Larson LM, Yaw Addo O, Sandalinas F, et al. Accounting for the influence of inflammation on retinol-binding protein in a population survey of Liberian preschool-age children. Matern Child Nutr. 2017;13(2):e12298. doi: 10.1111/mcn.12298

6. Wirth JP, Rohner F, Woodruff BA, Chiwile F, Yankson H, Koroma AS et al. Anemia, micronutrient deficiencies, and malaria in children and women in Sierra Leone prior to the Ebola outbreak - findings of a cross-sectional study. PLoS ONE. 2016;11(5):e0155031. doi: 10.1371/journal.pone.0155031

7. Petry N, Jallow B, Sawo Yankuba, et al. Micronutrient deficiencies, nutritional status and the determinants of anemia in children 0-59 months of age and non-pregnant women of reproductive age in the Gambia. Nutrients. 2019;11(10):2275. doi: 10.3390/nu11102275

8. Wegmüller R, Bentil H, Wirth JP, et al. Anemia, micronutrient deficiencies, malaria, hemoglobinopathies and malnutrition in young children and non-pregnant women in Ghana: findings from a national survey. PLoS ONE. 2020;15(1):e0228258. doi: 10.1371/journal. pone.0228258

9. Rohner F, Northrop-Clewes C, Tschannen AB, et al. Prevalence and public health relevance of micronutrient deficiencies and undernutrition in pre-school children and women of reproductive age in Côte d'Ivoire, West Africa. Public Health Nutr. 2014;17(9):2016-28. 


\section{doi: $10.1017 / \mathrm{S} 136898001300222 \mathrm{X}$}

10. Martin-Prevel Y, Allemand P, Nikiema L, et al. Biological status and dietary intakes of iron, zinc and vitamin A among women and preschool children in rural Burkina Faso. PLoS One. 2016;11(3):e0146810. doi 10.1371/journal.pone.0146810

11. Maziya-Dixon BB, Akinyele IO, Sanusi RA, Oguntona TE, Nokoe SK, Harris EW. Vitamin A deficiency is prevalent in children less than $5 \mathrm{y}$ of age in Nigeria. J Nutr. 2006;136:2255-2261. doi: 10.1093/ jn/136.8.2255

12. Alaofè H, Burney J, Naylor R, Taren D. Prevalence of anaemia, deficiencies of iron and vitamin $A$ and their determinants in rural women and young children: a cross-sectional study in Kalalé district of northern Benin. Public Health Nutr. 2017;20(7):1203-1213. doi: $10.1017 / \mathrm{S} 1368980016003608$

13. Danneskiold-Samsøe N, Fisker AB, Jørgensen MJ, et al. Determinants of vitamin A deficiency in children between 6 months and 2 years of age in Guinea-Bissau. BMC Public Health. 2013;13:172. doi: 10.1186/1471-2458-13-172

14. Schémann JF, Banou AA, Guindo A, Joret V, Traore L, Malvy D. Prevalence of undernutrition and vitamin A deficiency in the Dogon region, Mali. J Am Coll Nutr. 2002;21(5):381-387. doi 10.1080/07315724.2002.10719239

15. Carlier C, Moulia-Pelat JP, Ceccon JF, et al. Prevalence of malnutrition and vitamin A deficiency in the Diourbel, Fatick, and Kaolack regions of Senegal: epidemiological study. Am J Clin Nutr. 1991;53(1):70-73. doi: $10.1093 / \mathrm{ajcn} / 53.1 .70$

16. Rankins J, Green NR, Tremper W, Stacewitcz-Sapuntzakis M, Bowen P, Ndiaye M. Undernutrition and vitamin A deficiency in the department of Linguère, Louga region of Sénégal. Am J Clin Nutr. 1993;58(1): 91 97. doi: 10.1093/ajen/58.1.91

17. Carlier C, Etchepare M, Ceccon JF, Amedee-Manesme O. Assessment of the vitamin A status of preschool and schoolage Senegalese children during a cross-sectional study. Int J Vitam Nutr Res. 1992;62(3): 209215.

18. Micronutrient Initiative (MI), United Nations Children's Fund (UNICEF). Vitamin A and mineral deficiency: a global damage assessment report. 2004.

19. World Health Organization (WHO). Global database on vitamin A deficiency: Senegal.

20. Gueye AL. Carences en fer, zinc et vitamine A chez les femmes rurales du département de Sédhiou, région de Kolda. Thèse de doctorat de 3ème Cycle de Nutrition et Alimentation. Faculté des Sciences et Techniques: Université Cheikh Anta Diop de Dakar, 2006.

21. Ndiaye S, Ayad M. Enquête démographique et de santé au Sénégal, 2005. Calverton, Maryland, USA: Ministère de la santé et de la prévention médicale, Centre de recherche pour le développement humain [Sénégal] et ORC Macro, 2006.

22. World Health Organization (WHO). Indicators for assessing vitamin A deficiency and their application in monitoring and evaluating intervention programs. Geneva: World Health Organization, 1996.

23. World Health Organization (WHO). Serum retinol concentrations for determining the prevalence of vitamin A deficiency in populations. Vitamin and Mineral Nutrition Information System. Geneva: World
Health Organization, 2011.

24. Filteau SM. Vitamin A and the acute-phase response. Nutrition 1999;15(4):326-328. doi: 10.1016/S0899-9007(99)00012-X

25. Thurnham DI, McCabe GP, Northrop-Clewes CA, Nestel P. Effects of subclinical infection on plasma retinol concentrations and assessment of prevalence of vitamin A deficiency: meta-analysis. Lancet. 2003;362(9401):2052-2058. doi: 10.1016/S0140-6736(03)15099-4

26. Agne-Djigo A, Idohou-Dossou N, Kwadjode KM, Tanumihardjo SA, Wade S. High prevalence of vitamin A deficiency is detected by the modified relative dose-response test in six-month-old Senegalese breast-fed infants. J Nutr. 2012;142(11):1991-1996. doi: 10.3945/ jn.112.166454

27. World Health Organization (WHO). Haemoglobin concentrations for the diagnosis of anaemia and assessment of severity. Vitamin and Mineral Nutrition Information System. Geneva: WHO 2011.

28. Namaste SML, Aaron GJ, Varadhan R, Peerson JM, Suchdev PS. Methodologic approach for the Biomarkers Reflecting Inflammation and Nutritional Determinants of Anemia (BRINDA) project. Am J Clin Nutr. 2017;106(Suppl):333S-47S. doi: 10.3945/ajcn.116.142273

29. Larson LM, Guo J, Williams AM, et al. Approaches to assess vitamin A status in settings of inflammation: Biomarkers Reflecting Inflammation and Nutritional Determinants of Anemia (BRINDA) project. Nutrients. 2018;10(8):1100. doi: 10.3390/nu10081100

30. Agence Nationale de la Statistique et de la Démographie (ANSD), ICF. Sénégal: Enquête démographique et de santé continue (EDS-Continue 2017). Rockville, Maryland, USA: ANSD et ICF, 2018.

31. Ministère de la Santé et de la Prévention (MSP). Plan national stratégique pour la survie de l'enfant 2007-2015. Ministère de la Santé et de la Prévention, 2007.

32. Tanumihardjo SA, Kaliwile C, Boy E, Dhansay MA, van Stuijvenberg ME. Overlapping vitamin A interventions in the United States, Guatemala, Zambia, and South Africa: case studies. Annals NY Acad Sci. 2019;1446(1):102-116. doi: 10.1111/nyas.13965

33. Tanumihardjo SA, Russell RM, Stephensen CB, et al. Biomarkers of nutrition for development (BOND) - Vitamin A review. J Nutr. 2016;146(9):1816S-48S. doi: 10.3945/jn.115.229708

34. Tanumihardjo SA. The dawn of a new era in vitamin A assessment. J Nutr. 2020;150(2):185-187. doi: 10.1093/jn/nxz283

35. Bhattacharya J, Currie J, Haider S. Poverty, food insecurity, and nutritional outcomes in children and adults. J Health Econ. 2004;23(4):839-862. doi: 10.1016/j.jhealeco.2003.12.008

36. Bain LE, Awah PK, Geraldine N et al. Malnutrition in sub-Saharan Africa: burden, causes and prospects. Pan Afr Med J. 2013;15:120. doi:10.11604/pamj.06/08/2013 .15.120.2535

37. Sena LP, Vanderjagt DJ, Rivera C, et al. Analysis of nutritional components of eight famine foods of the Republic of Niger. Plant Foods Hum Nutr. 1998;52(1):17-30. doi: 10.1023/A: 1008010009170

38. Gronowska-Senger A, Wolf G. Effect of dietary protein on the enzyme from rat and human intestine which converts b-carotene to retinol. J Nutr. 1970;100(3):300-308. doi: 10.1093/jn/100.3.300

39. World Health Organization (WHO), Food and Agriculture Organization of the United Nations (FAO). Vitamin and mineral requirements in human nutrition, Second edition. Geneva: World 
Health Organization, 2004.

40. Sommer A, Davidson FR. Assessment and control of vitamin A deficiency: the Annecy accords. J Nutr. 2002;132(9 suppl):2845S2850S. doi: 10.1093/jn/132.9.2845S

41. Nguyen PH, Nguyen H, Gonzalez-Casanova I, et al. Micronutrient intakes among women of reproductive age in Vietnam. PLoS ONE. 2014;9(2):e89504. doi: 10.1371/journal.pone.0089504

42. Hodges RE, Sauberlich HE, Canham JE, et al. Hematopoietic studies in vitamin A deficiency. Am J Clin Nutr. 1978;31(5):876-885. doi: 10.1093/ajcn/31.5.876

43. Semba RD, Bloem MW. The anemia of vitamin A deficiency: epidemiology and pathogenesis. Eur J Clin Nutr. 2002;56(4):271-281. doi: $10.1038 /$ sj.ejcn. 1601320

44. Wirth JP, Woodruff BA, Engle-Stone R, et al. Predictors of anemia in women of reproductive age: Biomarkers Reflecting Inflammation and Nutritional Determinants of Anemia (BRINDA) project. Am J Clin Nutr. 2017;106(Suppl 1):416S-427S. doi: 10.3945/ajcn.116.143073

45. Dreyfuss ML, Stoltzfus RJ, Shrestha JB, et al. Hookworms, malaria and vitamin A deficiency contribute to anemia and iron deficiency among pregnant women in the plains of Nepal. J Nutr. 2000;130(10):25272536. doi: $10.1093 /$ jn $/ 130.10 .2527$
46. Radhika MS, Bhaskaram P, Balakrishna N, Ramalakshmi BA, Devi S, Kumar BS. Effects of vitamin A deficiency during pregnancy on maternal and child health. BJOG. 2002;109(6):689-693. doi: 10.1111/j.1471-0528.2002.01010.x

47.Jafari SM, Heidari G, Nabipour I, et al. Serum retinol levels are positively correlated with hemoglobin concentrations, independent of iron homeostasis: a population-based study. Nutr Res. 2013;33(4):279285. doi: 10.1016/j.nutres.2013.02.004

48. Ahmed F, Mahmuda I, Sattar A, Akhtaruzzaman M. Anaemia and vitamin A deficiency in poor urban pregnant women of Bangladesh. Asia Pac J Clin Nutr. 2003;12(4):460-466.

49. Yang C, Chen J, Liu Z, Yun C, Piao J, Yang X. Prevalence and influence factors of vitamin A deficiency of Chinese pregnant women. Nutr J 2016;27;15:12. doi: 10.1186/s12937-016-0131-7

50. Bastos Maia S, Costa Caminha MF, Lins da Silva S, Rolland Souza AS, Carvalho Dos Santos C, Batista Filho M. The prevalence of vitamin A deficiency and associated factors in pregnant women receiving prenatal care at a reference maternity hospital in northeastern Brazil. Nutrients. 2018,10(9):1271. doi: 10.3390/nu10091271

51. International vitamin A consultative group. Vitamin A and iron interactions. IVACG Statement. 